\title{
Lawsonia intracellularis associated equine proliferative enteropathy in Danish weanling foals
}

\author{
Anna Margareta Bohlin ${ }^{1 *}$, Susanne Nautrup Olsen², Sigrid Hyldahl Laursen², Anna Öhman \\ and Gaby van Galen ${ }^{2,3}$
}

\begin{abstract}
Background: Lawsonia intracellularis, an obligate intracellular bacterium, causes equine proliferative enteropathy, mainly in horses around weaning. This disease is rarely reported in the Scandinavian countries.

Results: Five cases of equine proliferative enteropathy were diagnosed between 2008-2016 at the University of Copenhagen Large Animal Teaching Hospital. Cases were Danish Warmbloods and a Friesian horse, aged 6-7 months, presenting with typical clinical signs of lethargy, poor body condition, pyrexia and diarrhea. Clinical pathology was consistent with previous reports of severe hypoalbuminemia and leukocytosis. Diagnosis was confirmed by fecal polymerase chain reaction, serum immunomonolayer peroxidase assay and/or immunofluorescence and fluorescence in situ hybridization performed on formalin-fixed ileum samples. Concurrent intestinal parasitism was present in all five cases. Treatment consisted of antimicrobial therapy, anti-inflammatories, intravenous crystalloids and plasma. Three foals were euthanised due to deterioration and poor response to treatment, one with complications of septic arthritis and Strongylus vulgaris associated intestinal infarct. The other two foals survived and were reported by the owners to be healthy on long-term follow-up.
\end{abstract}

Conclusions: Equine proliferative enteropathy is a disease to consider in young horses presenting with diarrhea and hypoproteinemia in Denmark.

Keywords: Diarrhea, Enteritis, Horse, Hypoalbuminemia, Hypoproteinemia

\section{Background}

Lawsonia intracellularis causes equine proliferative enteropathy (EPE), mainly in foals around weaning [1]. The bacterium is an obligate intracellular curved Gram-negative rod [2], and infects enterocytes primarily in the ileum and distal jejunum [3,4] causing a proliferation of the intestinal mucosal layer and subsequent malabsorption.

Typical associated clinical signs are lethargy, anorexia, pyrexia, peripheral edema, diarrhea, colic and weight loss [1, 4-6]. The most common clinicopathological findings include severe hypoalbuminemia and leukocytosis [1,

\footnotetext{
*Correspondence: anna.bohlin@evidensia.se

${ }^{1}$ Evidensia Equine Specialist Hospital Helsingborg, Bergavägen 3, 254 66 Helsingborg, Sweden

Full list of author information is available at the end of the article
}

7], and abdominal ultrasound typically reveals increased small intestinal wall thickness $[5,7,8]$. Fecal polymerase chain reaction (PCR) and/or serum immunomonolayer peroxidase assay (IMPA) can be used to confirm the infection ante-mortem $[1,6,9,10]$. Post-mortem the disease can be diagnosed by identifying $L$. intracellularis with Warthin-Starry staining (WS), immunofluorescence (IF) or fluorescence in situ hybridization (FISH) associated with proliferative lesions in the small intestine [11-15]. Treatment is by antimicrobials that achieve high intracellular concentrations [16], alongside supportive treatment with intravenous crystalloids, plasma or colloids [5].

EPE causes disease ranging from subclinical to acute and fatal [17-19]. The disease has been described as emerging in the North American horse population [20], 
with larger outbreaks described in the United States [8] and Canada [4]. Additionally, single cases have been reported from Switzerland [21], England [22], Belgium [23], Israel [24], Brazil [25] and Australia [26]. In Denmark, a previous seroprevalence study showed that $5 \%$ of young horses admitted to a Danish referral hospital (University of Copenhagen Large Animal Teaching Hospital) had measurable $L$. intracellularis serum antibodies [27]. However, this study was not linked to diagnosis or clinical signs. Since multiple porcine studies show a 100\% specificity and no cross reactions with other pathogens for IMPA serology [28, 29], this seroprevalence study is strongly suggestive for Danish foals being exposed to the bacterium, although the test may act differently in foals compared to pigs. Reports of $L$. intracellularis infection in foals in Scandinavia is limited to a Swedish fecal PCR study on 108 clinically healthy foals $4-8$ months old from four breeding farms, reporting only negative results [30] and a single short proceeding abstract where $L$. intracellularis was identified in post-mortem samples of two Danish foals [15].

Due to the lack of peer-reviewed reports of EPE in Scandinavia, the main objective of this study was to describe the clinical aspects of confirmed cases of $L$. intracellularis infection associated with EPE in a Danish referral population.

\section{Case presentations}

Between 2008-2016 a total of five cases of EPE were diagnosed during hospitalization $(n=3)$ or retrospectively by IMPA on stored frozen serum samples and/or IF and FISH on formalin-fixed ileum samples $(n=2)$ at the University of Copenhagen Large Animal Teaching Hospital.

Cases were 6-7 months-old Danish Warmbloods and one Friesian horse, four colts and one filly, all from different premises. Cases presented in October to January in $2008(\mathrm{n}=1), 2012(\mathrm{n}=1), 2015(\mathrm{n}=2)$ and $2016(\mathrm{n}=1)$.

Mean duration of disease noted by the owner before admission was 3 days. Four cases had been treated by referring veterinarian with non-steroidal anti-inflammatory drugs (flunixin meglumine or meloxicam), and three with antimicrobials (sulfadiazine-trimethoprim or penicillin procaine) before admission. Two had received anthelmintics within 2 weeks prior to presentation (ivermectin or fenbendazole).

Confirmed cases all displayed clinical signs of lethargy, pyrexia, tachycardia and peripheral edema. A summary of clinical signs is presented in Table 1.

All cases presented with hypoalbuminemia, hyponatremia, hypomagnesemia, hypocalcemia, increased fibrinogen and variably increased serum amyloid A, as shown in Table 2. Hypoalbuminemia became more
Table 1 Clinical signs, diagnostic tests, post-mortem findings and outcome in foals with equine proliferative enteropathy $(n=5)$

\begin{tabular}{ll}
\hline Parameter & EPE positive ( $\mathbf{n = 5 )}$ \\
\hline Clinical sign & \\
Lethargy & $5 / 5(100 \%)$ \\
Anorexia & $5 / 5(100 \%)$ \\
Poor body condition & $4 / 5(80 \%)$ \\
Peripheral edema & $5 / 5(100 \%)$ \\
Colic & $3 / 5(60 \%)$ \\
Diarrhea & $4 / 5(80 \%)$ \\
Pyrexia (>38.3 $\left.{ }^{\circ} \mathrm{C}\right)$ & $5 / 5(100 \%)$ \\
Diagnostic tests & \\
Intestinal parasitism ${ }^{\mathrm{a}}$ & \\
$\quad$ Overall & $5 / 5(100 \%)$ \\
$\quad$ Strongyles & $4 / 5(80 \%)$ \\
Parascaris spp. & $1 / 5(20 \%)$ \\
Abdominal ultrasound & \\
Increased small intestine wall thickness & $4 / 4(100 \%)$ \\
$\quad(\geq 4$ mm) & \\
Post-mortem examination & \\
Small intestine & \\
Increased wall thickness & \\
Large intestine & $3 / 3(100 \%)$ \\
Colitis & \\
Outcome & $2 / 3(67 \%)$ \\
Survival & \\
\hline PE &
\end{tabular}

EPE equine proliferative enteropathy

${ }^{a}$ Eggs, larvae or adult parasites found in feces or in the intestinal wall

profound during hospitalization for all cases (10.0$15.0 \mathrm{~g} / \mathrm{L}$ ). Four cases presented initially with normal leukocyte counts, however, three developed leukocytosis during the course of disease $\left(17.0-28.5 \times 10^{9}\right.$ cells/L).

Three cases had feces sampled for L. intracellularis real time PCR (Laboklin Gmbh \& Co, Bad Kissingen, Germany) within the first $48 \mathrm{~h}$ of admission, confirming EPE. For the other two cases testing for L. intracellularis was not performed during hospitalization. A summary of diagnostic tests performed for included cases is presented in Table 3.

Concurrent intestinal parasitism was present in all five cases with either strongyles (240-300 eggs per gram (EPG) or grossly present on necropsy) or Parascaris spp. (340 EPG). Three cases (case 1, 2 and 4) had a fecal culture for Salmonella spp. performed and one (case 2) had Clostridium difficile toxin A and B and Clostridium perfringens enterotoxin analyzed, but all were found negative. Peritoneal fluid was analyzed for four cases (case 1-3 and 5). The sample was mildly inflammatory in case 5 , for the others samples were within normal limits. Abdominal ultrasound (Fig. 1) was performed in four cases (case 1-3 
Table 2 History, clinical signs, laboratory values (at admission) and clinical pathology of foals with equine proliferative enteropathy $(n=5)$

\begin{tabular}{|c|c|c|c|c|c|}
\hline Parameter & Unit & Reference & Mean \pm SD & Range & Number \\
\hline \multicolumn{6}{|l|}{ History } \\
\hline $\begin{array}{l}\text { Duration of disease before admission } \\
\text { (days) }\end{array}$ & & - & $3 \pm 2$ & 1 to 7 & 5 \\
\hline \multicolumn{6}{|l|}{ Clinical signs } \\
\hline Heart rate & Bpm & $28-44$ & $58 \pm 9$ & 48 to 76 & 5 \\
\hline Respiratory rate & Rpm & $12-24$ & $18 \pm 5$ & 12 to 24 & 5 \\
\hline \multicolumn{6}{|l|}{ Complete blood count and biochemistry } \\
\hline Packed cell volume & $L / L$ & $0.32-0.50$ & $0.41 \pm 0.07$ & 0.37 to 0.52 & 5 \\
\hline Leukocyte count & $10^{9} / \mathrm{L}$ & $5.45-12.65$ & $11.51 \pm 3.14$ & 8.47 to 17.00 & 5 \\
\hline Neutrophil count & $10^{9} / \mathrm{L}$ & $2.26-7.22$ & $6.13 \pm 3.47$ & 1.20 to 10.80 & 5 \\
\hline Serum protein & $g / L$ & 57.0-74.0. & $30.1 \pm 4.2$ & 25.1 to 34.6 & 5 \\
\hline Albumin & $g / L$ & $28.0-40.0$ & $15.8 \pm 2.8$ & 13.0 to 19.7 & 5 \\
\hline Fibrinogen & $g / L$ & $0.0-4.0$ & $6.3 \pm 2.2$ & 4.2 to 10.6 & 5 \\
\hline Serum amyloid $A$ & $\mathrm{mg} / \mathrm{L}$ & $0-30$ & $943 \pm 1366$ & 108 to 3643 & 5 \\
\hline Iron & $\mu \mathrm{mol} / \mathrm{L}$ & $13.1-43.0$ & $10.0 \pm 3.4$ & 4.0 to 12.8 & 5 \\
\hline Gamma-glutamyl transferase & $\mathrm{U} / \mathrm{L}$ & $4-19$ & $6 \pm 2$ & 4 to 8 & 4 \\
\hline Total bilirubin & $\mu \mathrm{mol} / \mathrm{L}$ & $0.0-52.0$ & $34.7 \pm 8.2$ & 22.7 to 41.9 & 5 \\
\hline Creatinine & $\mu \mathrm{mol} / \mathrm{L}$ & $30-130$ & $102 \pm 18$ & 80 to 129 & 5 \\
\hline Creatinine kinase & $U / L$ & $0-348$ & $267 \pm 127$ & 134 to 487 & 5 \\
\hline Asparate transaminase & $U / L$ & $228-366$ & $168 \pm 38$ & 128 to 227 & 5 \\
\hline Sodium & $\mathrm{mmol} / \mathrm{L}$ & $136-142$ & $122 \pm 3$ & 119 to 126 & 5 \\
\hline Potassium & $\mathrm{mmol} / \mathrm{L}$ & $2.6-5.0$ & $3.1 \pm 0.4$ & 2.8 to 3.8 & 5 \\
\hline Chloride & $\mathrm{mmol} / \mathrm{L}$ & 99-109 & $98 \pm 4$ & 93 to 105 & 5 \\
\hline lonised calcium & $\mathrm{mmol} / \mathrm{L}$ & $1.40-1.72$ & $1.26 \pm 0.08$ & 1.14 to 1.34 & 5 \\
\hline Total magnesium & $\mathrm{mmol} / \mathrm{L}$ & $0.66-0.95$ & $0.43 \pm 0.08$ & 0.29 to 0.52 & 5 \\
\hline Lactate & $\mathrm{mmol} / \mathrm{L}$ & $0.0-2.0$ & $2.8 \pm 2.0$ & 0.7 to 6.2 & 5 \\
\hline Glucose & $\mathrm{mmol} / \mathrm{L}$ & $4.3-9.0$ & $7.8 \pm 2.4$ & 6.5 to 11.3 & 5 \\
\hline $\mathrm{pH}$ & & $7.32-7.55$ & $7.32 \pm 0.07$ & 7.20 to 7.40 & 5 \\
\hline Bicarbonate & $\mathrm{mmol} / \mathrm{L}$ & $24.0-30.0$ & $20.0 \pm 1.5$ & 18.0 to 22.0 & 4 \\
\hline Base excess & & $-4.0-4.0$ & $-6.1 \pm 0.9$ & -7.1 to -6.2 & 3 \\
\hline Triglycerides & $\mathrm{mmol} / \mathrm{L}$ & $0.1-0.9$ & $0.7 \pm 0.1$ & 0.6 to 0.8 & 2 \\
\hline \multicolumn{6}{|l|}{ Peritoneal fluid } \\
\hline Protein & $g / L$ & $0.0-10.0$ & $4.5 \pm 7.8$ & 0.0 to 18.0 & 4 \\
\hline Total nucleated cell count & $10^{9} / \mathrm{L}$ & $0.0-10.0$ & $5.3 \pm 6.2$ & 0.2 to 14.2 & 3 \\
\hline
\end{tabular}

Italics text: value outside reference range

Table 3 Diagnostic test results of foals diagnosed with equine proliferative enteropathy 2008-2016

\begin{tabular}{lllllllll}
\hline Case & $\begin{array}{l}\text { Age } \\
\text { (months) }\end{array}$ & Outcome & Fecal rtPCR & IMPA (admission) & IMPA (8 weeks) & WS $^{\mathbf{a}}$ & IF $^{\mathbf{a}}$ & FISH $^{\mathbf{a}}$ \\
\hline 1 & 7 & $\mathrm{NS}$ & Positive & $1: 100$ & $\mathrm{NP}$ & Negative & Negative & Negative \\
2 & 6 & $\mathrm{~S}$ & Positive & $<1: 25$ & $\mathrm{NP}$ & $\mathrm{NP}$ & $\mathrm{NP}$ & $\mathrm{NP}$ \\
3 & 6 & $\mathrm{~S}$ & Positive & $1: 50$ & $1: 200$ & $\mathrm{NP}$ & $\mathrm{NP}$ & $\mathrm{NP}$ \\
4 & 7 & $\mathrm{NS}$ & $\mathrm{NP}$ & $1: 480$ & $\mathrm{NP}$ & $\mathrm{Negative}$ & Positive & Negative \\
5 & 6 & $\mathrm{NS}$ & $\mathrm{NP}$ & $<1: 25$ & $\mathrm{NP}$ & $\mathrm{NP}$ & Positive & Positive \\
\hline
\end{tabular}

Italics: confirmative of equine proliferative enteropathy

NS non-survival, S survival, $r t P C R$ real time polymerase chain reaction, IMPA immunomonolayer peroxidase assay, WS Warthin-Starry staining, IF immunofluorescence, FISH fluorescence in situ hybridization, NP not performed

a Formalin-fixed ileum samples 

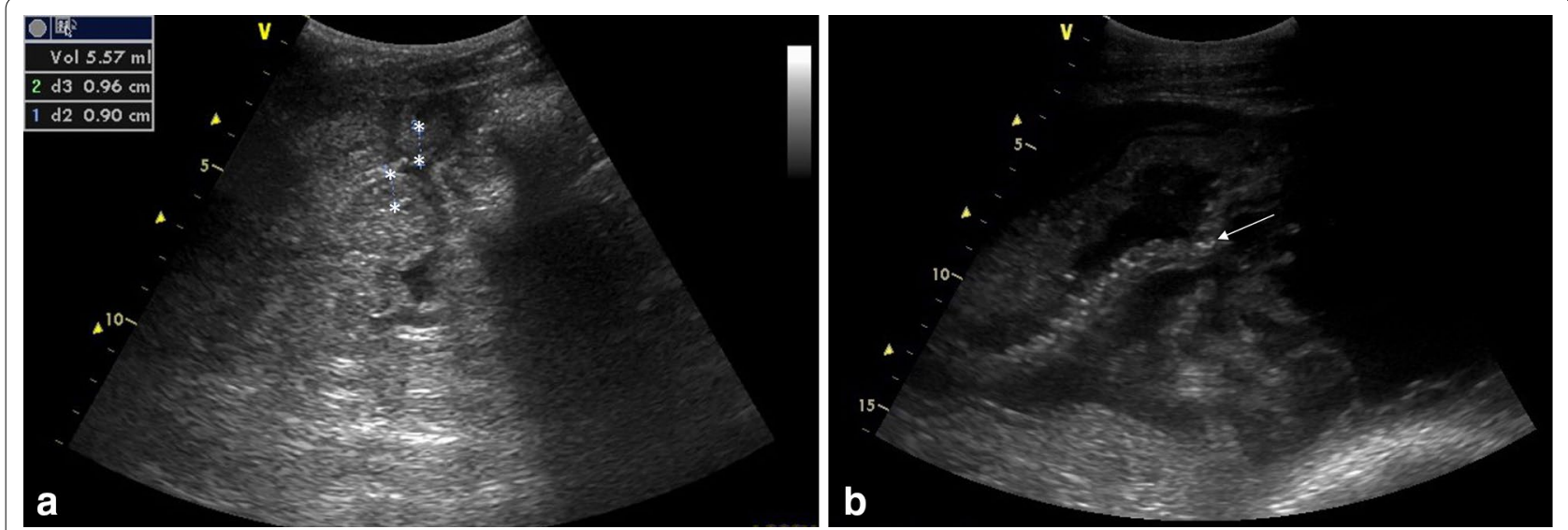

Fig. 1 Ultrasound images obtained in a foal with confirmed Lawsonia intracellularis infection. a Cross sectional view of small intestines with increased wall thickness of $0.9 \mathrm{~cm}$ (asterisk). $\mathbf{b}$ Longitudinal view of a small intestinal wall with increased echogenicity and thickness (arrow)

and 5) and showed increased small intestinal wall thickness for all $(0.5-0.9 \mathrm{~cm}$; normal range $0.2-0.3[31])$.

All five cases were treated with nonsteroidal antiinflammatories (flunixin meglumine ${ }^{1}$ or meloxicam ${ }^{2}$ ), crystalloids (Ringer's-acetate ${ }^{3}$ or sodium chloride $0.9 \%{ }^{4}$ ) and colloids (hetastarch $6 \%{ }^{5}$ and equine plasma ${ }^{6}$ ). Partial parenteral nutrition was provided with glucose $50 \%{ }^{7}$ or amino acids $11.4 \%^{8}$ for three foals (case $1-3$ ). One surviving foal (case 3) initially received benzyl penicil$\operatorname{lin}^{9}$ and gentamicin ${ }^{10}$ but was changed to rifampin ${ }^{11}$ and clarithromycin ${ }^{12}$ when EPE was suspected on day 2. Due to poor response, the foal received oxytetracycline ${ }^{13}$ from day 4 . The other surviving foal (case 2) was treated with oxytetracycline (see Footnote 13). One non-surviving foal received erythromycin ${ }^{14}$ and rifampin (see Footnote 11) (case 1), one received benzyl penicillin

\footnotetext{
${ }^{1}$ Findyne $50 \mathrm{mg} / \mathrm{mL}$, Intervet.

${ }^{2}$ Metacam $20 \mathrm{mg} / \mathrm{mL}$, Boehringer Ingelheim Vetmedica.

${ }^{3}$ Ringer-acetat Fresenius Kabi, Fresenius Kabi.

${ }^{4}$ Natriumklorid $9 \mathrm{mg} / \mathrm{mL}$, Fresenius Kabi.

${ }^{5}$ Voluven $60 \mathrm{mg} / \mathrm{mL}$, Fresenius Kabi.

${ }^{6}$ Hypermune Equine Plasma, Veterinary Immunogenics.

${ }^{7}$ Glucos $500 \mathrm{mg} / \mathrm{mL}$, Fresenius Kabi.

${ }^{8}$ Vamin 18 g N/I elektrolytfri, Fresenius Kabi.

9 Benzyl penicillin $1.2 \mathrm{~g}$, Panpharma.

${ }^{10}$ Genta-Equine $100 \mathrm{mg} / \mathrm{mL}$, Dechra.

11 Rimactan $300 \mathrm{mg}$, Sandoz.

12 Clarithromycin $500 \mathrm{mg}$, Orion Pharma.

${ }^{13}$ Engemycin $100 \mathrm{mg} / \mathrm{mL}$, Intervet.

${ }^{14}$ Hexabotin 500 mg, Durascan.

15 Antepsin $1 \mathrm{~g}$, Orion Pharma.
}

and metronidazole (case 5) and the last non-survivor did not receive antimicrobial treatment (case 4). Additionally, sucralfate ${ }^{15}$ omeprazole $^{16}$ and oral electrolytes were given to four cases. Three cases showed signs of colic at several occasions and were administered metamizole $^{17}$ butorphanol $^{18}$ and butylscopolamine ${ }^{19}$ Additionally, treatment with dexamethasone ${ }^{20}$ enoxaparin $^{21}$ glutamin $^{22}$, neostigmine ${ }^{23}$ calcium gluconate ${ }^{24}$ lidocain $^{25}$ and bicarbonate was provided. Three foals were given anthelmintics during hospital stay (moxidectin ${ }^{26}$ and fenbendazole ${ }^{27}$ ) and one foal received anthelmintic treatment after discharge.

Three foals (case 1, 4 and 5) were euthanised after 4-5 days of treatment, due to sudden deterioration and poor prognosis. Post-mortem examination of case 4 showed severe generalized edema and grossly increased small intestinal wall thickness. Histopathology of the duodenum and jejunum showed muscular hypertrophy, and in the ileum a few mineralized foci and a crypt abscess was found, however samples had autolytic changes and could not be fully evaluated. On retrospective analysis of serum, the foal had an IMPA titer of 480 (normal range: <60 [1, 6]) (National Veterinary

\footnotetext{
${ }^{16}$ GastroGuard $370 \mathrm{mg} / \mathrm{g}$, Merial.

17 Vetalgin $500 \mathrm{mg} / \mathrm{mL}$, Intervet.

18 Torbugesic $10 \mathrm{mg} / \mathrm{mL}$, Orion Pharma.

19 Buscopan $20 \mathrm{mg} / \mathrm{mL}$, Boehringer Ingelheim.

${ }^{20}$ Dexadreson $2 \mathrm{mg} / \mathrm{mL}$, Intervet.

${ }^{21}$ Klexane $100 \mathrm{mg} / \mathrm{mL}$, Sanofi.

22 L-Glutamine, Scientec Nutrition.

${ }^{23}$ Neostigmin $2.5 \mathrm{mg} / \mathrm{mL}$, SAD.

${ }^{24}$ Calciject 40, Norbrook.

25 Lidocain $20 \mathrm{mg} / \mathrm{mL}$, Mylan.

${ }^{26}$ Equest 18.9\%, Orion Pharma Animal Health.

27 Panacur 18.5\%, MSD Animal Health.
} 
Laboratory, Technical University of Denmark (NVL)) and was positive by IF on formalin-fixed samples of the ileum (NVL).

Gross pathology of case 5 showed cachexia, hypertrophy of the small intestinal mucosa and multiple encysted cyathostomins in the colon wall. Histopathology of small intestinal sections were unremarkable, but formalin-fixed samples from the ileum were positive for L. intracellularis by IF and FISH.

Case 1 presented with additional symptoms to the classical signs of EPE, with a respiratory noise from moderate airway edema at admission. This foal was diagnosed with EPE based on a positive fecal PCR and a serum IMPA titer of 100 . On day 3 of hospitalization, this foal developed septic arthritis of the tarsocrural joint. On the 4th day of treatment the foal's general condition rapidly worsened with circulatory compromise and development of severe pulmonary edema. Due to poor response to treatment, the foal was euthanised. Post-mortem examination showed gross generalized edema and increased small intestinal wall thickness. Additionally, the foal had peritonitis and an arterial thrombus causing infarction of the pelvic flexure of the colon. In the ileocolic artery, there was evidence of chronic arteritis with aneurysms and thrombi containing Strongylus vulgaris larvae. Histopathology showed generalized thickened small intestine with chronic ulcerative enteritis and lymphocytic hyperplasia. Testing for L. intracellularis by IF and FISH was negative for this case.

The two surviving foals (case 2 and 3) were hospitalized for 5 and 11 days, respectively. Case 3 had a re-visit 8 weeks after discharge where it was found clinically normal except for poor body condition and mild exfoliative dermatitis of the cannon bones and ear tips. Abdominal ultrasound was normal, complete blood count and biochemistry showed normal albumin $(28.9 \mathrm{~g} / \mathrm{L})$ and leukocytes $\left(10.1 \times 10^{9}\right.$ cells $\left./ \mathrm{L}\right)$, and mildly increased fibrinogen level $(5.1 \mathrm{~g} / \mathrm{L})$. Serology at this time point revealed an IMPA titer of 200 compared to the admission titer of 50 (Laboklin Gmbh \& Co). On follow-up 1 year later the owner reported the colt to be healthy with a normal body condition. Case 3 had follow-up examination 4 days after discharge, where ultrasound showed small intestinal thickening to have decreased, and serum albumin to be low but stable $(15.0 \mathrm{~g} / \mathrm{L})$. Approximately 2 years after discharge the owner was contacted by telephone and reported the colt to be healthy.

Comparing blood samples between surviving and non-surviving cases, these were not different regarding severity of leukocytosis, hypoproteinemia, hypoalbuminemia, fibrinogen or serum amyloid A values.

\section{Discussion and conclusions}

To the authors' knowledge, this is the first peer-reviewed report describing the clinical aspects of foals with $L$. intracellularis associated EPE in Scandinavia. This study supports that $L$. intracellularis not only circulates and foals are in contact with the bacterium, but also causes clinical disease (EPE) in Denmark. Therefore, EPE should be considered a differential diagnosis in Danish weanlings.

Lawsonia intracellularis is present in the majority (94\%) of Danish pig farms [32]. A screening for L. intracellularis was performed on stored serum samples at the Large Animal Teaching Hospital, University of Copenhagen from horses admitted 2005-2008, regardless of health status and/or diagnosis. Five percent of horses between 0 days and 24 months of age had detectable antibodies by IMPA [27]. It has been shown in experimental studies that porcine strains can cause disease in horses [13], however, equine strains cause more severe disease [33], and is genetically slightly different from the porcine strains [34]. In the confirmed EPE cases of this report, there was no known association with pigs, and no strain assessment was performed.

Compared to reports from the USA and Canada $[4,8]$, only few cases were found in this study and none of them occurred in outbreaks. Yet, the cases presented were all within the expected age group of around 6 months, and presented at the time of year when EPE is most frequently reported in other studies (September-January) [1]. Confirmed cases showed the typical clinical signs associated with EPE with lethargy, anorexia, pyrexia, peripheral edema, colic and diarrhea [1, 17], and the typical clinicopathological findings of hypoalbuminemia and leukocytosis [1]. For cases where abdominal ultrasound was performed, marked thickening of the small intestinal wall was seen. This is reported a common finding in EPE cases, with reports of wall thickness of up to $1.0 \mathrm{~cm}$ [5, $7,8,35]$. However, in some cases abdominal ultrasound is normal despite confirmed EPE, whereby this technique cannot be used to rule out the disease $[1,17]$. Abdominal ultrasound is an important diagnostic tool and should be performed in cases suspected of EPE.

Fecal real time PCR was used to diagnose EPE in three of the reported cases; the other cases described in the current study did not have fecal samples submitted. The fecal PCR assays have been evaluated in pigs, showing very high specificity in several studies (100\%), whereby false positives are unlikely [36-38]. The reported sensitivity is lower, ranging from $71 \%$ (early), and $38 \%$ (later) in the course of disease [11]. In studies of equine weanlings, 
including only cases with positive serology and clinical signs suggestive of EPE, 74-79\% of fecal samples were positive on PCR $[1,6]$. There is a greater chance of positive fecal PCR if cases are sampled early in the course of disease, and before treatment with antimicrobials [1]. Our positive cases were sampled the day after arrival and had only received trimethoprim-sulfadiazine and penicillin procaine, i.e. antimicrobials without intracellular penetration.

An additional ante-mortem diagnostic method is serology by IMPA. In this study two different laboratories performed the IMPA analyses, with results reported in different dilutions of 50 or 60 . In previous studies, foals have been considered seroconverted when IMPA titers were $\geq 60[1,6]$, and higher titers have correlated with more severe disease [17]. Recently also an enzyme-linked immunosorbent assay test was validated for the detection of L. intracellularis antibodies in horses [9]. Serology in the current study was confirmative of EPE for three cases (titers 100-480). In one of these, the titer was below 60 on admission, but was significantly increased when remeasured 8 weeks later (50 compared to 200). The largest study on EPE published had $80 \%$ of cases positive by IMPA, and explained negative results most likely being a result of too early sampling [1]. In an experimental study, antibodies by IMPA in weanling's after challenge with $L$. intracellularis was first detected after 2-3 weeks [17]. This could potentially explain the low titers in two cases positive by real time PCR or IF and FISH (case 2 and 5), with short duration of disease before admission, where detectable antibodies may not yet have been produced.

In this study, three techniques for post-mortem identification of $L$. intracellularis on formalin-fixed ileum samples were used. Warthin-Starry staining yielded negative results in the three non-surviving cases that were positive by other ante-mortem (real time PCR or IMPA) or post-mortem tests (IF and FISH). All post-mortem tests rely on the presence of bacteria or bacterial antigen in the tissue, with IF and FISH considered more sensitive and specific compared to WS [11, 12]. Previous antimicrobial treatment could have affected the results, since it has been reported that infected foals stop shedding the organism within 4 days after treatment is initiated [39]. The one foal positive by fecal real time PCR and serum IMPA (case 1) but negative on post-mortem tests, had received antimicrobial treatment (erythromycin and rifampin) with a duration of 4 days before euthanasia, possibly explaining these negative post-mortem findings.

Diagnosis of EPE is furthermore complicated by concomitant diseases with similar clinical presentation that frequently occur in foals, especially intestinal parasitism. This is well described in the literature $[1,3-5,7$, $8]$, and is also a finding in the current study. This can account for underdiagnosing of EPE. Concurrent intestinal parasitism with strongyles or Parascaris spp. was found in all cases, making parasitism one of the major differential diagnoses of EPE. It should be stressed that in the case of cyathostomiasis in foals within the age group 4-8 months, additional testing for EPE should be performed. It may be speculated that concurrent intestinal parasitism could make the foal more susceptible to L. intracellularis infection. In one non-surviving EPE case in the current study, chronic arteritis of the ileocolic artery and thrombi associated with $S$. vulgaris was diagnosed at necropsy. This was likely an important contributing factor to the deterioration and subsequent euthanasia of this foal. In the literature, there is evidence of coagulation disturbances in the form of epistaxis and hematochezia [19] and infarction from arterial thrombi $[1,3,8]$ associated with EPE. This has been reported in severely affected cases with suspicion of translocation of bacteria over the inflamed and infected intestinal mucosa, and subsequent sepsis [19]. In these cases, the formation of thrombi has been attributed to severe hypoproteinemia and depletion of coagulation factors, along with severe systemic inflammatory response syndrome (SIRS) due to sepsis. Our case had evidence of necrotizing enteritis on post-mortem examination, and evidence of sepsis from a septic joint. To our knowledge, this is the first case presented with confirmed EPE and concurrent $S$. vulgaris associated thromboembolism. However, it cannot be completely ruled out that thrombi and deterioration was also caused by sepsis and SIRS.

Based on the severity of hematologic and biochemistry changes, it was not possible to distinguish survivor from non-survivors in the current case series. Survival was only $40 \%$ in the current study, a low number in comparison to the $93 \%$ previously reported in a study of 57 EPE affected foals from the USA [1]. Survival may have been affected by the advanced state of disease on admission, the choice of antimicrobials (both surviving foals were treated with oxytetracycline, and non-survivors instead received penicillin, metronidazole, erythromycin, rifampin or no antimicrobials), or the coinciding pathologies. Unfortunately, the low number of included foals prevented statistical analysis of risk factors. However, long term prognosis for survivals seemed favorable, with the two surviving foals reported to be healthy on followup 1 and 2 years later.

Limitations of this study are mainly due to the partially retrospective nature, including lack of some clinical and laboratory data and inconsistent diagnostic testing. Testing all suspected cases by fecal PCR early in disease, and later by serum IMPA, would have 
been preferable to establish diagnosis and optimize treatment.

In Denmark, L. intracellularis was confirmed to cause clinical disease (EPE) in five weanling foals. Concurrent intestinal parasitism, an important differential diagnosis, was present in all foals. Therefore, the possibility of EPE should be considered in foals that are presented with diarrhea, pyrexia and/or severe hypoalbuminemia in this country, even if a diagnosis of intestinal parasitism has been made already. Presentation was similar as in other parts of the world, with good response of the survivors in long term.

\section{Abbreviations \\ EPE: equine proliferative enteritis; FISH: fluorescence in situ hybridization; IF: immunofluorescence; IMPA: immunomonolayer peroxidase assay; NVL: National Veterinary Laboratory, Technical University of Denmark; PCR: poly- merase chain reaction; SIRS: severe inflammatory response syndrome; WS: Warthin-Starry staining.}

\section{Authors' contributions}

$A M B$ and GvG presented the idea, designed the study, drafted the manuscript and contributed to final manuscript preparation. AMB, GVG and SHL examined, sampled and treated the included cases and contributed to follow-up of patients. SNO, SHL and AÖ contributed to final manuscript preparation. All authors read and approved the final manuscript.

\section{Author details}

1 Evidensia Equine Specialist Hospital Helsingborg, Bergavägen 3, 25466 Helsingborg, Sweden. ${ }^{2}$ Large Animal Teaching Hospital, Department of Veterinary Clinical Sciences, University of Copenhagen, Agrovej 8, 2630 Taastrup, Denmark. ${ }^{3}$ Present Address: Faculty of Science, Sydney School of Veterinary Science, The University of Sydney, 410 Werombi Road, Camden, NSW, Australia.

\section{Acknowledgements}

The authors wish to acknowledge the veterinary clinicians, veterinary technicians and students at the University of Copenhagen Large Animal Teaching Hospital. Also, we want to acknowledge the Department of Veterinary and Animal Sciences, section of Pathobiological Sciences at the University of Copenhagen for performing post-mortem examinations of the included non-surviving cases and the National Veterinary Laboratory for performing IF and FISH.

\section{Competing interests}

The authors declare that they have no competing interests.

\section{Availability of data and materials}

The datasets used and analyzed in the current study are available from Susanne Nautrup Olsen on reasonable request.

\section{Consent for publication}

All owners gave consent for publication, except for one owner that was not reachable.

\section{Ethics approval and consent to participate}

This is a retrospective case series of patients admitted to the University of Copenhagen Large Animal Teaching Hospital without the use of new or experimental treatments, therefore no ethics approval is available.

\section{Funding}

The study was funded by the Department of Veterinary Clinical Sciences, University of Copenhagen and the National Veterinary Institute, Technical University of Denmark.

\section{Publisher's Note}

Springer Nature remains neutral with regard to jurisdictional claims in published maps and institutional affiliations.

Received: 23 September 2018 Accepted: 27 February 2019

Published online: 08 March 2019

\section{References}

1. Frazer ML. Lawsonia intracellularis infection in horses: 2005-2007. J Vet Intern Med. 2008;22:1243-8.

2. Lawson GHK, Gebhart CJ. Proliferative enteropathy. J Comp Path. 2000;122:77-100.

3. Arroyo LG, ter Woort F, Baird JD, Tatiersky L, DeLay J, van Dreumel T. Lawsonia intracellularis-associated ulcerative and necro-hemorrhagic enteritis in 5 weanling foals. Can Vet J. 2013;54:853-8.

4. Lavoie JP, Drolet R, Parsons D, Léguillette R, Sauvageau R, Shapiro J, et al. Equine proliferative enteropathy: a cause of weight loss, colic, diarrhoea and hypoproteinemia in foals on three breeding farms in Canada. Equine Vet J. 2000;32:418-25.

5. Atherton RP, McKenzie HC III. Alternative antimicrobial agents in the treatment of proliferative enteropathy in horses. J Equine Vet Sci. 2006;26:535-41.

6. Pusterla N, Mapes S, Johnson C, Slovis N, Page A, Gebhart C. Comparison of feces versus rectal swabs for the molecular detection of Lawsonia intracellularis in foals with equine proliferative enteropathy. J Vet Diagn Invest. 2010;22:741-4.

7. Sampieri F, Hinchcliff KW, Toribio RE. Tetracycline therapy of Lawsonia intracellularis enteropathy in foals. Equine Vet J. 2006;38:89-92.

8. Merlo JL, Sheats MK, Elce Y, Hunter S, Breuhaus BA. Outbreak of Lawsonia intracellularis on a Standardbred breeding farm in North Carolina. Equine Vet Educ. 2009;21:179-82.

9. Hassenin ASH, Sena S, Gebhart CJ, Goyal SM. Comparison of ELISA and IPMA tests for the detection of anti-Lawsonia antibodies in horses. IJOART. 2017;6:17-24.

10. Jones GF, Ward GE, Murtaugh MP, Lin G, Gebhart CJ. Enhanced detection of intracellular organism of swine proliferative enteritis, ileal symbiont intracellularis, in feces by polymerase chain reaction. J Clin Microbiol. 1993;31:2611-5.

11. Guerdes RMC, Gebhart CJ, Winkelman NL, Mackie-Nuss RAC, Marsteller TA, Deen J. Comparison of different methods for diagnosis of porcine proliferative enteropathy. Can J Vet Res. 2002;66:99-107.

12. Jensen TK, Moller K, Lesser TD, Jorsal SE. Comparison of histology, immunohistochemistry and polymerase chain reaction for detection of Lawsonia intracellularis in natural porcine proliferative enteropathy. Eur J Vet Pathol. 1997;3:115-23.

13. Al-Ghamdi GM, Guerdes RMC, Sage AM, Hayden DW, Neubauer A, Ames TR. Reproduction of proliferative enteropathy in foals after challenge with Lawsonia intracellularis infected porcine intestinal mucosae homogenate. B J Vet Med. 2012;15:273-82.

14. Jensen TK, Boesen HT, Vigre $H$, Boye M. Detection of Lawsonia intracelIularis in formalin-fixed porcine intestinal tissue samples: comparison of immunofluorescence and in situ hybridization, and evaluation of the effects of controlled autolysis. J Comp Path. 2009;142:1-8.

15. Jensen TK. Lawsonia intracellularis enteritis in two Danish foals. J Comp Pat. 2015;152:82.

16. Weese JS. Antimicrobial therapy for difficult to identify and atypical pathogens. Equine Vet Educ. 2009;21:388-92.

17. Pusterla N, Wattanaphansak S, Mapes S, Collier J, Hill J, DiFrancesco M, et al. Oral infection of weanling foals with an equine isolate of Lawsonia intracellularis, agent of equine proliferative enteropathy. J Vet Intern Med. 2010;24:622-7.

18. Page AE, Loynachan AT, Bryant U, Stills HF Jr, Adams AA, Gebhart CJ, et al. Characterization of the interferon gamma response to Lawsonia intracellularis using an equine proliferative enteropathy challenge (EPE) model. Vet Immunol Immunopathol. 2011;143:55-65.

19. Page AE, Fallon LH, Bryant UK, Horohov DW, Luna TW, Marsh PS, et al. Acute deterioration and death with necrotizing enteritis associated 
with Lawsonia intracellularis in 4 weanling horses. J Vet Intern Med. 2012;26:1476-80.

20. Pusterla N, Gebhart CJ. Equine proliferative enteropathy—a review of recent developments. Equine Vet J. 2013;45:403-9.

21. Wuersch K, Hussey D, Koch C, Overmann A. Lawsonia intracellularis proliferative enteropathy in a filly. J Vet Med A Physiol Pathol Clin Med. 2006:53:17-21.

22. Allen KJ, Pearson GR, Fews D, McOrist S, Brazil TJ. Lawsonia intracellularis proliferative enteropathy in a weanling foal, with a tentative histological diagnosis of lymphocytic plasmacytic enteritis. Equine Vet Educ. 2009:21:411-4.

23. Deprez P, Chiers K, Gebhart CJ, Ducatelle D, Lefere L, Vanschandevijl K, et al. Lawsonia intracellularis infection in a 12-month- old colt in Belgium. Vet Rec. 2005:157:774-6.

24. Steinman A, Aharonson-Raz K, Blum SE, Shnaiderman A, Klement E, Lensky IM, et al. Demographic and environmental risk factors for exposure to Lawsonia intracellularis in horses in Israel. J Equine Vet Sci. 2014;34:641-6.

25. Gabardo MP, Sato JPH, Resende TP, Guedes RMC. Equine proliferative enteropathy on a Brazilian farm. Pesq Vet Bras. 2015;35:443-7.

26. McClintock SA, Collins AM. Lawsonia intracellularis proliferative enteropathy in a weanling foal in Australia. Aust Vet J. 2004;82:750-2.

27. Olsen $\mathrm{SN}$, Jungersen $\mathrm{G}$, Jensen TK. Lawsonia intracellularis enteritis in foals in Denmark. Dansk Vet Tidsskr. 2009;92:37 (in Danish).

28. Guerdes RCM, Gebhart CJ, Deen J, Winkelman N. Validation of an immunoperoxidase monolayer assay as a serologic test for porcine proliferative enteropathy. J Vet Diagn Invest. 2002;14:528-30.

29. Magtoto RL, Vegi A, Wang C, Johnson JK, Ramamoorthy S. Evaluation and use of a serological assay for the detection of antibodies to Lawsonia intracellularis in swine. Int J Vet Sci Med. 2014:2:109-13.
30. Johansson T, RåsbäckT, Roneus M, Fellström C, Jacobson M. Presence of Lawsonia intracellularis and Brachyspira spp in horses. Svensk Vet Tidni. 2006:10:11-5 (in Swedish)

31. Aleman M, Gillis CL, Nieto JE, Renaudin CD, Bea J. Ultrasonographic anatomy and biometric analysis of the thoracic and abdominal organs in healthy foals from birth to age 6 months. Equine Vet J. 2002;34:649-55.

32. Stege $H$, Jensen TK, Moller K, Baekbo $P$, Jorsal SE. Prevalence of intestinal pathogens in Danish finishing pig herds. Prev Vet Med. 2017;46:1-14.

33. Vannucci FA, Pusterla N, Mapes SM. Evidence of host adaptation in Lawsonia intracellularis infections. Vet Res. 2012;43:1-9.

34. Mirajkar NS, Kelley MR, Gebhart CJ. Draft genome sequence of Lawsonia intracellularis strain E40504, isolated from a horse diagnosed with equine proliferative enteropathy. Genome Announc. 2017;5:e00330-417.

35. Schumacher J, Rolsma M, Brock KV, Gebhart CJ. Surgical and medical treatment of an Arabian filly with proliferative enteropathy caused by Lawsonia intracellularis. J Vet Intern Med. 2000;14:630-2.

36. Jordan DM, Knittel JP, Roof MB, Schwartz K, Larson D, Hoffman LJ. Detection of Lawsonia intracellularis in swine using polymerase chain reaction methodology. J Vet Diagn Invest. 1999;11:45-9.

37. McOrist S, Gebhart CJ, Lawson GH. Polymerase chain reaction for diagnosis of porcine proliferative enteropathy. Vet Microbiol. 1994;41:205-12.

38. Moller K, Jensen TK, Jorsal SE, Leser TD, Carstensen B. Detection of Lawsonia intracellularis, Serpulina hyodysenteriae, weakly beta-haemolytic intestinal spirochaetes, Salmonella enterica, and haemolytic Escherichia coli from swine herds with and without diarrhoea among growing pigs. Vet Microbiol. 1998;62:59-72.

39. Dauvillier J, Picandet V, Harel J, Gottschalk M, Desrosiers R, Jean D, et al. Diagnostic and epidemiological features of Lawsonia intracellularis enteropathy in 2 foals. Can Vet J. 2008;47:689-91.
Ready to submit your research? Choose BMC and benefit from:

- fast, convenient online submission

- thorough peer review by experienced researchers in your field

- rapid publication on acceptance

- support for research data, including large and complex data types

- gold Open Access which fosters wider collaboration and increased citations

- maximum visibility for your research: over $100 \mathrm{M}$ website views per year

At BMC, research is always in progress.

Learn more biomedcentral.com/submissions 